\title{
Live Attenuated Influenza Vaccines against Highly Pathogenic H5N1avian Influenza: Development and Preclinical Characterization
}

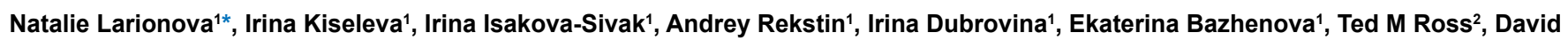
Swayne $^{3}$, Larisa Gubareva ${ }^{4}$, Vadim Tsvetnitsky ${ }^{5}$, Ekaterina Fedorova ${ }^{1}$, Elena Doroshenko ${ }^{1}$ and Larisa Rudenko ${ }^{1}$

${ }^{1}$ Institute of Experimental Medicine, St. Petersburg, Russia

${ }^{2}$ University of Pittsburgh, Pittsburgh, PA, USA

${ }^{3}$ Southeast Poultry Research Laboratory, Athens, GA, USA

${ }^{4}$ Centers for Disease Control and Prevention, Atlanta, GA, USA

${ }^{5}$ PATH (Program for Appropriate Technologies in Health), USA

\begin{abstract}
In this paper we describe the development and the outcomes of the preclinical studies of temperature-sensitive and cold-adapted candidates for live attenuated influenza vaccine (LAIV) based on highly pathogenic avian influenza viruses A/H5N1 with pandemic potential. The LAIV candidates were developed by methods of classical reassortment between H2N2 Master Donor Virus for Russian LAIV and H5N1 viruses generated by reverse genetics for inactivated vaccine. These reverse genetically generated viruses were chosen as a source of $\mathrm{H} 5$ hemagglutinin and contained a modified protease cleavage site believed to be associated with high virulence. The progeny of reassortment had 7:1 gene composition and were characterized by antigen specificity of the HA of the pandemic virus, a high growth rate in chicken embryos and their parameters of temperature sensitivity and cold adaptation confirmed preserved attenuation of the Master Donor Virus. In addition, one H5N1 LAIV 6:2 reassortant was generated by reverse genetics. When tested in appropriate animal models, all candidates for H5N2 LAIV vaccine were found to be safe, immunogenic and effective in protecting from severe disease, mortality and pathology caused by the homologues lethal challenge virus and they almost completely eliminated challenge virus replication in vaccinated animals. They did not appear to differ in tested properties from the reverse genetically generated H5N1 LAIV 6:2 reassortant which contained wild-type N1-neuraminidase in addition to H5-hemagglutinin. The most promising for further clinical trials has been considered a LAIV candidate to virus A/turkey/Turkey/1/2005 (H5N1, clade 2.2).
\end{abstract}

Keywords: Live attenuated influenza vaccine; Potential pandemic vaccines; Highly pathogenic avian influenza virus; Master donor virus; Attenuated; Temperature sensitive; Cold-adapted phenotype

Abbreviations: LAIV: Live Attenuated Influenza Vaccine; HPAIV: Highly Pathogenic Avian Influenza Virus; MDV: Master Donor Virus; Att: Attenuated; Ts: Temperature Sensitive; Ca: Cold-Adapted Phenotype

\section{Introduction}

In the last decade, a dangerous epizootic situation associated with the spread among wild migratory birds of the highly pathogenic strains of influenza virus has developed on the Eurasian and African continents. $\mathrm{A} / \mathrm{H} 5 \mathrm{~N} 1$ highly pathogenic avian influenza viruses (HPAIVs) are frequent cause of outbreaks in poultry and potentially are threat to humans. The spread of these viruses in bird populations, the likelihood of reassortment with other influenza viruses of birds and mammals, coupled with contact virus transmission from birds to humans, as well as the high mortality case ratio among infected people, raised fears and significant concerns for global public health [1]. Although sustained human-to-human transmission of HPAIV has not occurred, there is evidence of limited person-to-person spread of infection [2]. Outbreaks of avian influenza in poultry raised additional concerns due to their detrimental effect on poultry populations, the possibility to cause serious disease in people, and their pandemic potential.

One of the strategies in the field of prevention of influenza infections is the creation of National bank of vaccines to potentially dangerous viruses for use in the event of an emergency need in the interpandemic or pandemic period $[3,4]$. In the event of a pandemic threat, the use of live attenuated cold-adapted reassortant influenza vaccine (LAIV) may have an advantage over inactivated vaccines due to its ability to provide a broader and more long-lasting cross protective immune response [5]. The LAIVs have been used extensively in Russia over 40 years to control seasonal influenza and shown to be safe, immunogenic, and highly protective among all populations, as well as providing a significant level of community-wide herd immunity [6,7].

The candidates for live attenuated influenza A vaccines in Russia are generated by methods of classical reassortment of epidemiologically relevant strains with comprehensively studied attenuated (att) temperature sensitive $(t s)$, cold-adapted ( $c a$ ) A/Leningrad/134/17/57 (H2N2) master donor virus (MDV-L17). MDV-L17 was derived from A/Leningrad/134/57 (H2N2) (Lwt) the wild type virus-precursor as a result of 17 passages in eggs reduced to a $25^{\circ} \mathrm{C}$ temperature. It differs from Lwt by eight coding mutations in internal genes. Mutations in the polymerase genes of MDV-L17 were found to be responsible for its att/ $t s / c a$ phenotype. Creation of $6: 2$ vaccine reassortant by replacement of internal genes of wild-type virus with the appropriate internal genes of MDV is a reliable and reproducible method of attenuation of wildtype viruses [8]. Internal viral proteins of MDV provide attenuation of

*Corresponding author: Natalie Larionova, Institute of Experimental Medicine (IEM), 12 Acad. Pavlov Street, Saint Petersburg, Russia, 197376, Tel: +7 812 2344292; Fax: +7 812 2349489; E-mail: nvlarionova@mail.ru

Received August 30, 2013; Accepted October 21, 2013; Published October 25 , 2013

Citation: Larionova N, Kiseleva I, Isakova-Sivak I, Rekstin A, Dubrovina I, et al. (2013) Live Attenuated Influenza Vaccines against Highly Pathogenic H5N1avian Influenza: Development and Preclinical Characterization. J Vaccines Vaccin 4: 208 doi: 10.4172/2157-7560.1000208

Copyright: (c) 2013 Larionova N, et al. This is an open-access article distributed under the terms of the Creative Commons Attribution License, which permits unrestricted use, distribution, and reproduction in any medium, provided the original author and source are credited. 
Citation: Larionova N, Kiseleva I, Isakova-Sivak I, Rekstin A, Dubrovina I, et al. (2013) Live Attenuated Influenza Vaccines against Highly Pathogenic H5N1avian Influenza: Development and Preclinical Characterization. J Vaccines Vaccin 4: 208. doi: 10.4172/2157-7560.1000208

Page 2 of 11

vaccine reassortant ensuring its safety [9], and surface glycoproteins, hemagglutinin (HA) and neuraminidase (NA) of the wild type virus provide the targets for an adequate immune response in vaccinated host.

To reduce a risk of manipulations with HPAIVs and to lower their pathogenicity to chick embryos, we generated cold-adapted LAIV candidates on the base of reverse genetically (RG) constructed H5N1 strains for inactivated vaccine (A/H5N1/PR8-RG), kindly provided by WHO (Geneva, Switzerland) and CDC (Atlanta, GA, USA). These RGvaccine strains are reassortants with internal proteins genes of highly reproductive strain A/Puerto Rico/8/34 (H1N1) (PR8) and the HA and NA of H5N1 HPAIV. Their safety is ensured by the fact that four basic amino acid codons from the cleavage site of $\mathrm{H} 5 \mathrm{HA}$, responsible for the pathogenicity of the virus, are removed as described [10]. Creating candidates LAIV vaccines on the basis of such RG-modified HPAIVs adds non-pathogenic features to $\mathrm{H} 5 \mathrm{~N} 1$ vaccines. However, in the process of LAIV candidate development in eggs, we encountered the difficulty of natural reassortment between H5N1/PR8-based influenza viruses and $\mathrm{H} 2 \mathrm{~N} 2 \mathrm{MDV}$. Our attempts to obtain 6:2 reassortants with HA and NA genes of avian origin by classical methods were unsuccessful. Finally, H5N2 reassortants with genomic composition 7:1 were obtained, which inherited HA gene of HPAIV and the remaining genes (including N2 neuraminidase) of the MDV-L17. Preclinical studies of two 7:1 (H5N2) LAIV candidates and one RG-generated 6:2 (H5N1) LAIV candidate are presented in this paper.

\section{Materials and Methods}

\section{Viruses}

MDV for Russian LAIV calts A/Leningrad/134/17/57 (H2N2) (MDV-L17); 6:2 vaccine reassortant A/17/Vietnam/1203/04-RG (H5N1) (VN/H5N1-RG LAIV), are the property of the Institute of Experimental Medicine (Saint Petersburg, Russia). VN/PR/CDCRG - A/Vietnam/1203/2004 (H5N1, clade 1)-based reassortant was generated at and obtained from the CDC (Atlanta, GA, USA). NIBRG-23 - A/turkey/Turkey/1/2005 (H5N1, clade 2.2)-based reassortant was generated at the NIBSC (UK) and obtained via the WHO. RG-generated reassortants are identified in the text as H5N1/ PR8-RG, while LAIV reassortants - as H5N2 LAIV or H5 LAIV candidates. H5N1/PR8-RG reassortants were generated by the reverse genetics technique from HPAIV A/H5N1 viruses, as a source of HA and NA, and A/Puerto Rico/8/34 (H1N1) strain which served as a donor of internal genes. Cleavage site of H5 HA gene of H5N1/PR8-RG reassortants was modified by removal of four basic amino acid codons associated with high virulence. All viruses were propagated in 10-11 day old embryonated chicken eggs. The following wild-type H5N1 influenza viruses were used in various tests: A/Vietnam/1203/2004 (clade 1), A/Vietnam/1194/2004 (clade 1), A/Indonesia/5/2005 (clade 2.1), A/whooper swan/Mongolia/244/2005 (clade 2.2), A/turkey/ Turkey/01/2005 (clade 2.2), A/bar-headed goose/Mongolia/1/2005 (clade 2.2), A/Anhui/1/2005 (clade 2.3), H1N1pdm09 viruses A/ California/07/2009, A/North Carolina/39/2009 and H1N1pdm09 LAIV A/17/California/2009/38.

\section{RG-generation of H5N1-LAIV reassortant}

VN/H5N1-RG LAIV 6:2 reassortant was generated on the base of HPAIV A/Vietnam/1203/2004 (H5N1) and cold-adapted MDV-L17 (H2N2) by plasmid-based reverse genetics. VN/H5N1-RG LAIV virus was rescued by co-transfecting plasmids encoding modified HA gene (polybasic cleavage site deleted) and intact NA gene of A/ Vietnam/1203/2004 (H5N1) with plasmids encoding six internal genes of MDV-L17, as described [11]. RG-derived virus was fully sequenced to confirm the absence of spontaneous mutations.

\section{Classical genetic reassortment procedure}

MDV-L17 and H5N1/PR8-RG viruses were co-infected in embryonated chicken eggs (CE) as previously described in more detail [12]. Five rounds of selective propagation were performed, three of which were at low temperature of $25-26^{\circ} \mathrm{C}$. The production and selection of reassortants was carried out in the presence of rabbit antiserum to MDV-L17. Cloning by endpoint dilutions was performed in each of the last three passages.

\section{Partial inactivation of parental virus by UV light}

Before co-infection NIBRG-23 virus was partially inactivated with ultraviolet light (GE 15 watt germicidal lamp; 20 seconds at a distance of $20 \mathrm{~cm}$ ) to lower the infectious titer by $6 \log _{10} \mathrm{EID}_{50} / \mathrm{ml}$ as described [13].

\section{Determining $t s / c a$ phenotype}

Capacity of LAIV reassortants and parental viruses to grow at optimum for $t s, c a$ viruses $\left(33^{\circ} \mathrm{C}\right)$, low $\left(25^{\circ} \mathrm{C}\right)$ and elevated $\left(38^{\circ} \mathrm{C}, 39^{\circ} \mathrm{C}\right.$ and $40^{\circ} \mathrm{C}$ ) temperatures was determined by titration in $\mathrm{CE}$. The $\log _{10}$ $\mathrm{EID}_{50} / \mathrm{ml}$ calculation was based on the Reed and Muench method [14].

Viruses were considered as possessing $t s$ phenotype if the titer at temperature $38^{\circ} \mathrm{C}$ and above was $\leq 4.2 \log _{10}$ EID $_{50} / \mathrm{ml}$ when titrated in 10-11 day old embryonated CE. Viruses were considered as having a $c a$ phenotype if the titer at low temperature of $25^{\circ} \mathrm{C}$ was $\geq 5.7 \log _{10} \mathrm{EID}_{50} /$ $\mathrm{ml}$.

\section{Hemagglutination inhibition (HAI) test}

Serum samples, RDE-treated (receptor-destroying enzyme, DenkaSeiken, Tokyo, Japan), were tested for hemagglutination inhibition specific antibodies by standard procedure [15] with $1.0 \%$ suspension of chicken or horse erythrocytes (HRBC) (Lampire Biologicals, Pipersville, PA, USA).

\section{Genome composition analysis}

RNA was isolated from influenza virus infected allantoic fluid by using QIAamp Viral RNA minikit (Qiagen GmbH, Hilden, Germany).

The parental origin of the RNA segments of each reassortant virus was monitored by RFLP analysis [16], or determined by mixed PCR assay [17] and partial sequencing.

\section{Nucleotide sequencing}

Sequencing of the viruses was performed by using a BigDye Terminator v3.1 cycle sequencing kit (Applied Biosystems) and a 3130xl Genetic Analyzer (Applied Biosystems) according to the instructions from the manufacturer. Multiple sequence alignment analysis was performed using Clone Manager 9.

\section{Susceptibility of LAIV candidates to neuraminidase inhibitors}

H5N2 LAIV reassortants were tested for the susceptibility to neuraminidase inhibitors (NAI) by the fluorescent neuraminidase inhibition assay (NI), using the NA-Fluor kit (ABI), as described in [18]. Interpretation of the NI assay results was done according to the WHO WER criteria [19] based on the fold change of the test virus IC50 values compared to reference IC50 values. For influenza A, use of 
normal ( $<10$-fold increase), reduced (10-100-fold increase) and highly reduced ( $>100$-fold increase) inhibition was recommended.

\section{Animals}

Mice (Balb/c mice): Female, 6-8 weeks of age were supplied by the Laboratory Animal Farm "RAPPOLOVO" (Rappolovo, North-West region, Russia).

Guinea pigs (Cavia porcellus): 5-6 weeks of age, 350-450 $\mathrm{g}$ of weight were supplied by the Laboratory Animal Farm "RAPPOLOVO" (Rappolovo, North-West region, Russia).

Chickens (Gallus domesticus): Specific pathogen free (SPF) White Leghorn, 5 and 6 weeks of age, were supplied by the Southeast Research Poultry Laboratory, GA, USA.

Ferrets (Mustela putorius furo): Female, 6-12 months of age were supplied by Triple-F Farms (Sayre, PA, USA) and prescreened to ensure that they were negative to circulating human influenza $\mathrm{A}$ and influenza B viruses, and to the virus being tested.

\section{Acute toxicity test}

The test was performed with a single vaccine candidate dose $(9.7$ $\log _{10} \mathrm{EID}_{50} / \mathrm{ml}$ ) delivered intraperitoneally to mice and intradermally to guinea pigs. Ten mice received one human dose in $0.5 \mathrm{ml}$ of $0.9 \%$ saline (representing approximately 2500 times greater dose than used in humans according to the weight difference coefficients). Ten guinea pigs received 10 human doses in $5 \mathrm{ml}$ of saline (or 1250 times higher dose than used in humans according to the weight difference coefficients). Control mice and guinea pigs received equivalent volume of sterile saline. The animals were observed on a daily basis for 7 days for clinical signs of toxicity, behavior, food and water uptake, and any weight change. Brain, heart, liver, kidney and spleen were collected from sacrificed animals at the end of the study for histopathology analysis.

\section{Sub-acute toxicity test}

Vaccine candidates $\left(8.7 \quad \log _{10} \quad \mathrm{EID}_{50} / \mathrm{ml}\right)$ were administered intranasally daily for 2 days, to mice $(0,025 \mathrm{ml}$ in each nostril) or guinea pigs $(0.25 \mathrm{ml}$ in each nostril). The vaccine volume administered to mice was $1 / 10$ of a typical single vaccine dose for humans (or 350 times higher amount according to the weight difference coefficients). The vaccine volume administered to guinea pigs was equivalent to a single human dose (or 200 times higher amount according to the weight difference coefficients). Overall health signs were observed and their body mass measured daily during the treatment and recovery period (12 days after the last the administration).

\section{Safety and attenuation study in chickens}

Ten 6-week-old chickens inoculated intravenously with 10 -fold diluted infective allantoic fluid $\left(6.7 \log _{10}\right.$ EID $\left._{50} / 1 \mathrm{ml}\right) 0.1 \mathrm{ml}$ per bird, of H5-LAIVs or parental viruses according to IVPI (intravenous pathogenicity index) protocol [20]. Birds were examined at 24hour intervals for 10 days. The IVPI is the mean score per bird per observation over the 10-day period. An index of 3.00 means that all birds died within 24 hours, and an index of 0.00 means that no bird showed any clinical sign during the 10-day observation period.

Ten 5-week-old birds vaccinated intranasally $\left(6.7 \log _{10} \operatorname{EID}_{50} / 1\right.$ ml) $0.1 \mathrm{ml}$ per bird of H5-LAIVs or parental viruses. Chickens were observed for 10 days. On the $3^{\text {rd }}$ day were collected samples of oral and cloacal swabs, and tissues of lungs, kidney, heart and brain from two sacrificed birds. Swab samples or ten times diluted tissue samples were inoculated for viral reproduction into 10-day old CE in $0.2 \mathrm{ml}$ (3 CE per sample). Blood samples were taken on day 14 after intranasal administration.

\section{Attenuation, immunogenicity and protection study in ferrets}

For attenuation study ferrets ( 6 animals per group) were vaccinated intranasally with 6.0 or $7.0 \log _{10} \mathrm{EID}_{50} /$ per animal of each H5-LAIV reassortant in $0.5 \mathrm{ml}$ volume. Animals were monitored daily for adverse events, weight loss and body temperature. Three ferrets from each group were euthanized on the day 3 and 5 after inoculation for lung viral titer determination and histopathological analysis. HPAIVs A/Vietnam/1194/2004 (H5N1), A/turkey/Turkey/1/2005 (H5N1) were used as pathogenic controls and LAIV A/17/California/2009/38 (H1N1) - as attenuated positive control in a dose of $7.0 \log _{10} \mathrm{EID}_{50}$. Negative control animals received equal volume of sterile saline solution as placebo.

For immunogenicity and protection study groups of animals (6 per group) were intranasally immunized with two doses of $7.0 \log _{10} \mathrm{EID}_{50}$ in $0.5 \mathrm{ml}$ volume H5-LAIV candidates 28 days apart. Blood samples were collected from anesthetized ferrets at day 28 (week 4) and at day 42 (week 6) post immunization. Samples were tested in HAI test with homologous and heterologous virus antigens. At day 42 ferrets were challenged with $6 \log _{10}$ PFU (plaque forming units) of the HPAIV A/ turkey/Turkey/01/2005 (H5N1) or A/turkey/Turkey/01/2005 (H5N1) in each nostril for a total infection volume of $0.5 \mathrm{ml}$. Control animals received equal volume of placebo. Ferrets were monitored daily for weight loss, disease signs and death for 14 days after the challenge as previously described [21]. Nasal washes were performed daily for 14 days. Three animals from each group were euthanized on day 3 post-infection and remaining animals that survived the challenge were sacrificed on day 14 post-infection. Samples of lungs and nasal turbinates were weighed and single cell suspensions were prepared via passage through a $70 \mu \mathrm{m}$ mesh (BD Falcon, Bedford, MA, USA) in an appropriate volume of iDMEM (DMEM supplemented with penicillin-streptomycin) as to achieve $100 \mathrm{mg} / \mathrm{ml}$ final concentration. Centrifuged supernatants of cell suspensions were collected.

Virus titers in lungs, nasal turbinates, and nasal wash samples were determined by plaque assay, as described [22,23] and PFU/g for lung and nasal turbinates tissues or PFU/ml for nasal washes calculated.

Histopathology analysis: Left lobes of lungs from infected ferrets were collected at 3 and 14 days post-infection with HPAIV H5N1 challenge virus. After fixation in $10 \%$ buffered formalin, lungs were paraffin embedded and $6 \mu \mathrm{m}$ sections were prepared for histopathological analysis. Tissue sections were stained with hematoxylin and eosin.

\section{Results}

\section{Development of reassortants for LAIVs}

As a result of classical reassortment of MDV-L17 with VN/PR/ CDC-RG six PR8- originating internal genes (PB2, PB1, PA, NP, M and NS) were replaced by the corresponding genes of the MDV-L17. Despite several selection rounds, all the resulting reassortants inherited neuraminidase gene (N2) of MDV (genomic composition 7:1). Reassortants with genomic composition $6: 2$ have not been obtained. 7:1 reassortant A/17/Vietnam/04/65107 (H5N2) (VN/H5N2 LAIV) was chosen as one LAIV candidate for further studies. 
Citation: Larionova N, Kiseleva I, Isakova-Sivak I, Rekstin A, Dubrovina I, et al. (2013) Live Attenuated Influenza Vaccines against Highly Pathogenic H5N1avian Influenza: Development and Preclinical Characterization. J Vaccines Vaccin 4: 208. doi: 10.4172/2157-7560.1000208

Page 4 of 11

The other PR8-based H5N1 virus, NIBRG-23 poorly reassorted with MDV-L17 (H2N2) based on the classical reassortmen procedure. Despite the selectivity factor (incubation temperature reduced to $25^{\circ} \mathrm{C}$ which is favorable for breeding reassortants on the basis of $c a$ MDV-L17), the parental virus NIBRG-23 fully displaced MDV-L17 during reassortment procedure and the overwhelming majority (209 of the 234) of finaly selected clones were NIBRG-23, 9 clones inherited a single PA gene of the MDV, 3 clones had a single NS gene of the MDV, and 13 clones were identical to the MDV-L17 (data not shown).

In order to create reassortants inheriting internal genes of the MDV and surface genes of the HPAIV, various modifications of co-infection stage were applied. Thus, we tested different ratios of parental viruses NIBRG-23 and MDV-L17 (from 1:1 to 1:106), different sequence of the parental virus infection of eggs (simultaniously, or MDV inoculation 30 min prior to NIBRG-23), application of various concentrations of antiserum to the MDV-L17, and adding extra amounts of the antiserum to PR8 virus. These manipulations did not lead to expected results. However, we had moderate success with NIBRG-23 virus partially inactivated by ultraviolet (UV) light to a residual titer $2.2 \log _{10}$ $\mathrm{EID}_{50} / \mathrm{ml}\left(6 \log _{10} \mathrm{EID}_{50}\right.$ reduction of titer). As a result of reassortment between the MDV and partially UV-inactivated NIBRG-23 at a ratio of 100:1, we isolated several "intermediate" reassortants (C2, C4, D1), that have inherited a number of internal genes of MDV-L17 (Table 1). Finally, back crossing of clones C2, C4 and D1 and MDV-L17 led to the obtaining reassortants with the genomic composition 7:1, which inherited all internal genes and the gene for NA from the MDV-L17. This 7:1 reassortant A/17/turkey/Turkey/05/133 (H5N2) (t/T/H5N2 LAIV) was chosen as another LAIV candidate for testing.

\section{Molecular genetic analysis of the LAIV candidates}

H5N2 LAIV candidates were fully sequenced. Checking the internal genes of reassortants for identity to parental viruses confirmed that the

\begin{tabular}{|c|c|c|c|c|c|c|c|c|}
\hline $\begin{array}{l}\text { Parental virus/ } \\
\text { reassortant }\end{array}$ & PB2 & PB1 & PA & HA & NP & NA & M & NS \\
\hline L17-MDV & ${\mathrm{L} 17^{1}}^{1}$ & L17 & L17 & L17 & L17 & L17 & L17 & L17 \\
\hline NIBRG-23 & $\mathrm{PR}^{2}$ & PR8 & PR8 & Tur- $r^{3}$ & PR8 & Tur $^{4}$ & PR8 & PR8 \\
\hline \multicolumn{9}{|c|}{ First step. Crossing NIBRG-23, UV-inactivated, and L17-MDV } \\
\hline Clone B3 & PR8 & PR8 & L17 & Tur-r & PR8 & Tur & PR8 & PR8 \\
\hline Clone C2 & PR8 & L17 & L17 & Tur-r & PR8 & Tur & PR8 & PR8 \\
\hline Clone C4 & L17 & L17 & L17 & Tur-r & PR8 & L17 & PR8 & L17 \\
\hline Clone D1 & PR8 & L17 & L17 & Tur-r & PR8 & Tur & L17 & PR8 \\
\hline \multicolumn{9}{|c|}{ Second step. Back crossing of clones from the "First step" with L17-MDV } \\
\hline Clone $\mathrm{C} 2 / 35$ & L17 & L17 & L17 & Tur-r & L17 & L17 & L17 & L17 \\
\hline Clone $\mathrm{C} 4 / 88$ & L17 & L17 & L17 & Tur-r & L17 & L17 & L17 & L17 \\
\hline Clone $\mathrm{D} 1 / 32$ & L17 & L17 & L17 & Tur-r & L17 & L17 & L17 & L17 \\
\hline Clone $\mathrm{D} 1 / 33$ & L17 & L17 & L17 & Tur-r & L17 & L17 & L17 & L17 \\
\hline
\end{tabular}

The origin of the genes encoding the corresponding proteins of the virus:

${ }^{1} \mathrm{~L} 17$ or L17-MDV corresponds to A/Leningrad/134/17/57 MDV (H2N2);

${ }^{2}$ A/Puerto Rico/8/34 (H1N1);

${ }^{3} \mathrm{RG}$-modified HA of non-pathogenic NIBRG-23 (H5N1);

${ }^{4} \mathrm{NA}$ of non-pathogenic NIBRG-23 (H5N1) identical to A/turkey/Turkey/1/2005 (H5N1).

Table 1: Generation of reassortants between NIBRG-23(H5N1) and L17-MDV(H2N2)

\begin{tabular}{|c|c|c|c|c|c|c|c|c|c|c|c|c|c|}
\hline \multirow[b]{2}{*}{ Gene } & \multicolumn{6}{|c|}{ Nucleotide } & \multirow[b]{2}{*}{ Protein } & \multicolumn{6}{|c|}{ Amino acid } \\
\hline & No. & Lwt $^{1}$ & L17-MDV ${ }^{2}$ & $\begin{array}{l}\text { VN/H5N1- } \\
\text { RG LAIV33 }\end{array}$ & $\begin{array}{c}\text { VN/H5N2 } \\
\text { LAIV }\end{array}$ & $\begin{array}{c}\text { t/T/H5N2 } \\
\text { LAIV }\end{array}$ & & No. & Lwt & L17-MDV & $\begin{array}{l}\text { VN/H5N1- } \\
\text { RG LAIV }\end{array}$ & $\begin{array}{c}\text { VN/H5N2 } \\
\text { LAIV }\end{array}$ & $\begin{array}{c}\text { t/T/H5N2 } \\
\text { LAIV }\end{array}$ \\
\hline PB2 & 1459 & G & $\mathrm{T}$ & $\mathrm{T}$ & $\mathrm{T}$ & $\mathrm{T}$ & PB2 & 478 & Val & Leu & Leu & Leu & Leu \\
\hline \multirow{4}{*}{ PB1 } & 360 & G & A & A & $A$ & A & \multirow{4}{*}{ PB1 } & 112 & Glu & Glu & Glu & Glu & Glu \\
\hline & 819 & G & $\mathrm{T}$ & $\mathrm{T}$ & $T$ & $\mathrm{~T}$ & & 265 & Lys & Asn & Asn & Asn & Asn \\
\hline & 1795 & G & A & A & $A$ & A & & 591 & Val & Ile & Ile & Ile & Ile \\
\hline & $1011^{*}$ & A & A & A & G & A & & $329^{*}$ & Gln & Gln & Gln & Gln & Gln \\
\hline \multirow{3}{*}{ PA } & 107 & $\mathrm{~T}$ & $\mathrm{C}$ & $\mathrm{C}$ & $\mathrm{C}$ & C & \multirow{3}{*}{ PA } & 28 & Leu & Pro & Pro & Pro & Pro \\
\hline & 222 & $\mathrm{~T}$ & C & C & $\mathrm{C}$ & C & & 66 & Asp & Asp & Asp & Asp & Asp \\
\hline & 1045 & G & $\mathrm{T}$ & $\mathrm{T}$ & $\mathrm{T}$ & $\mathrm{T}$ & & 341 & Val & Leu & Leu & Leu & Leu \\
\hline \multirow{2}{*}{ NA } & $765^{*}$ & G & G & G & $T$ & $\mathrm{~T}$ & \multirow{2}{*}{ NA } & 249 & $\operatorname{Arg}$ & Arg & Arg & Ile & Ile \\
\hline & 1116 & $\mathrm{~T}$ & C & $C$ & C & C & & 366 & Ile & Thr & Thr & Thr & Thr \\
\hline \multirow{2}{*}{$M$} & 68 & A & $G$ & G & $G$ & $G$ & \multirow{2}{*}{ M1 } & 15 & Ile & Val & Val & Val & Val \\
\hline & 457 & $T$ & G & G & G & $G$ & & 144 & Phe & Leu & Leu & Leu & Leu \\
\hline NS & 798 & $\mathrm{G}$ & $A$ & A & $A$ & $A$ & NS2 & 100 & Met & Ile & Ile & Ile & Ile \\
\hline \multirow{2}{*}{$\mathrm{HA}$} & $50^{*}$ & - & - & $T$ & $C$ & - & \multirow{2}{*}{$\mathrm{HA}$} & 8 & - & - & Phe & Leu & - \\
\hline & $417^{*}$ & - & - & $\mathrm{T}$ & $C$ & - & & 130 & - & - & Ile & Thr & - \\
\hline
\end{tabular}

Symbols are used here and in the following Tables and Figures: ${ }^{1}$ Lwt corresponds to A/Leningrad/134/57 (H2N2) wild-type virus, a precursor of $A / L$ eningrad/134/17/57 (H2N2) MDV; ${ }^{2}$ L17-MDV corresponds to A/Leningrad/134/17/57 (H2N2) MDV;

${ }^{3}$ VN/H5N1-RG LAIV corresponds to A/17/Vietnam/1203/04-RG (H5N1) LAIV candidate;

${ }^{4}$ VN/H5N2 LAIV corresponds to A/17/Vietnam/04/65107 (H5N2) LAIV candidate;

5t/T/H5N2 LAIV corresponds to A/17/turkey/Turkey/05/133 (H5N2) LAIV candidate.

*additional mutations of H5N2 LAIV candidates

Table 2: Nucleotide and amino acid differences between A/Leningrad/134/57(H2N2) wild-type virus, A/Leningrad/134/17/57(H2N2) MDV, and H5-LAIV candidates. 
VN/H5N2 LAIV- and t/T/H5N2 LAIV-candidates inherited all the genes of internal and non-structural proteins of MDV-L17. All coding nucleotide substitutions characterized for $c a$, ts MDV-L17 (Table 2), are present in the genes of internal and non-structural proteins of H5N2 LAIV-candidates.

The sequencing of HA gene confirmed the absence of a factor of pathogenicity - four basic amino acids codons in the proteolytic cleavage site of the HA molecule (data not shown), thereby bringing additional confidence in attenuated properties to the LAIV reassortants. The NA gene sequencing confirmed the origin of the NA gene of reassortants VN/H5N2 LAIV and t/T/H5N2 LAIV to the parental MDV-L17.

A small number of additional nucleotide changes were acquired during the reassortment procedures. VN/H5N2 LAIV acquired 4 additional mutations in PB1 (1), HA (2) and NA (1) genes, while t/T/ H5N2 LAIV acquired a single additional mutation in NA gene (Table 2). Therefore, a nucleotide substitution at position G-765-T of NA gene, corresponding to an amino acid substitution at position Arg-249-Ile, is common for both chosen LAIV candidates reassortants. This mutation should not have any significant effect on the antigenic and essential for the vaccine virus's functional properties [24]. The mutation in PB1 gene position 1011 of VN/H5N2 LAIV is not coding, whereas mutations in HA gene led to amino acid changes. T-50-C mutation in HA gene leads to amino acid substitution in HA0 precursor, but this mutation is located in a signal peptide which is removed during HA molecule processing. The T-417-C mutation leads to amino acid change in HA1 molecule (Ile-114-Thr). This mutation is located far from key residues which could potentially affect receptor-binding affinity and specificity of the virus $[25,26]$ and can be considered as not significant.

Therefore, full-genome sequencing of both 7:1 vaccine reassortants did not reveal significant changes which can alter anticipated virus immunogenic properties.

The 6:2 reassortant VN/H5N1-RG LAIV virus was fully sequenced and the absence of any unwanted spontaneous mutations and quasispecies was confirmed.

\section{Genetic stability of H5 LAIV candidates}

Five serial passages of the LAIV reassortants at $33^{\circ} \mathrm{C}$ in eggs were performed to assess their genetic stability. It was confirmed by RFLP analysis and partial sequencing of the genes fragments that all nucleotide substitutions responsible for MDV-L17 (H2N2) attenuating phenotype $[9,27]$ are preserved in the genome of VN/H5N2 LAIV, VN/H5N1-RG LAIV and t/T/H5N2 LAIV candidates after passages at optimal temperature (Table 3 ).

\section{Phenotypical study of H5 LAIV candidates in vivo}

The results of titration of LAIV reassortants and parental viruses in $\mathrm{CE}$ at different temperatures are presented in Table 4. It was demonstrated that 7:1 H5N2 LAIV as well as 6:2 VN/H5N1-RG LAIV reassortants exhibit high growth rate at the temperature of $33^{\circ} \mathrm{C}$ which is optimal for $c a$, ts MDV-L17. The optimum temperatures for the parental avian influenza viruses growth cover the wide range $\left(33-38^{\circ} \mathrm{C}\right)$, whereas reproduction of all LAIV reassortants and MDV already at $37^{\circ} \mathrm{C}$ is reduced by more than $4 \log _{10} \operatorname{EID}_{50}$ (confirming ts-phenotype). Like MDV-L17, H5 LAIV reassortants grew well at a reduced temperature of $25^{\circ} \mathrm{C}$ (demonstrating ca-phenotype). On the contrary, H5N1 wild-type parents were characterized by decreased reproduction at $25^{\circ} \mathrm{C}$. These data indicate that VN/H5N2 LAIV and t/T/H5N2 LAIV candidates with 7:1 genomic composition and the 6:2 reassortant VN/H5N2-RG LAIV have the same ca/ts phenotype specific to the cold-adapted parental MDV-L17.

\section{Assessment of susceptibilities to neuraminidase inhibitors of H5 LAIVs candidates}

Sequence analysis of the NA gene revealed no known molecular markers associated with reduced susceptibility to NAIs [24]. To rule

\begin{tabular}{|c|c|c|c|c|c|c|c|c|c|c|}
\hline \multirow{3}{*}{ Gene } & \multirow{3}{*}{ Nucleotide } & \multirow{3}{*}{$\begin{array}{l}\text { Amino acid } \\
\text { position }\end{array}$} & \multicolumn{8}{|c|}{ Amino acid substitutions in the internal genes of the virus } \\
\hline & & & \multirow{2}{*}{ Lwt $^{1}$} & \multirow{2}{*}{ L17-MDV } & \multicolumn{6}{|c|}{ LAIV candidate (\# of passage) } \\
\hline & & & & & VN/H5N2 (0) & VN/H5N2 (5) & $\mathrm{t} / \mathrm{T} / \mathrm{H} 5 \mathrm{~N} 2(0)$ & t/T/H5N2 (5) & VN/H5N1-RG (0) & VN/H5N1-RG ( 5) \\
\hline PB2 & 1459 & 478 & Val & Leu & Leu & Leu & Leu & Leu & Leu & Leu \\
\hline \multirow[t]{2}{*}{ PB1 } & 819 & 265 & Lys & Asn & Asn & Asn & Asn & Asn & Asn & Asn \\
\hline & 1795 & 591 & Val & Ile & Ile & Ile & Ile & Ile & Ile & Ile \\
\hline \multirow[t]{2}{*}{ PA } & 107 & 28 & Leu & Pro & Pro & Pro & Pro & Pro & Pro & Pro \\
\hline & 1045 & 341 & Val & Leu & Leu & Leu & Leu & Leu & Leu & Leu \\
\hline NP & \multicolumn{10}{|c|}{ NP gene of Len17-MDV(H2N2) does not contain coding mutations } \\
\hline \multirow{2}{*}{ M1 } & 68 & 15 & Ile & Val & Val & Val & Val & Val & Val & Val \\
\hline & 457 & 144 & Phe & Leu & Leu & Leu & Leu & Leu & Leu & Leu \\
\hline NS2 & 798 & 100 & Met & Ile & Ile & Ile & Ile & Ile & Ile & Ile \\
\hline
\end{tabular}

Table 3: Genetic stability of coding mutations in the internal genes of H5-LAIV candidates after the 5 -fold passages in the developing chick embryos at $32^{\circ} \mathrm{C}$.

\begin{tabular}{|c|c|c|c|c|c|c|c|}
\hline \multirow{2}{*}{ Virus } & \multirow{2}{*}{$\begin{array}{l}\text { Virus titer at } 33^{\circ} \mathrm{C} \text {, } \\
\quad \log _{10} \mathrm{EID}_{50} / \mathrm{ml}\end{array}$} & \multicolumn{5}{|c|}{$\mathrm{RCT}^{1}$} & \multirow{2}{*}{ Phenotype } \\
\hline & & $33 / 37^{\circ} \mathrm{C}$ & $33 / 38^{\circ} \mathrm{C}$ & $33 / 39^{\circ} \mathrm{C}$ & $33 / 40^{\circ} \mathrm{C}$ & $33 / 25^{\circ} \mathrm{C}$ & \\
\hline L17-MDV (H2N2) & 9.2 & 5.0 & 6.0 & 7.0 & 7.5 & 2.5 & ts, ca \\
\hline NIBRG-23 (H5N1) & 6.2 & 0 & 0 & 4,7 & 6.2 & 4.0 & non-ts, non-ca \\
\hline VN/PR/CDC-RG (H5N1) & 7.7 & 1.0 & 1.0 & 7.7 & 7.7 & 4.0 & non-ts, non-ca \\
\hline t/T/H5N2 LAIV & 8.7 & 4.5 & 5.7 & 8.7 & 8.7 & 1.5 & ts, ca \\
\hline VN/H5N2 LAIV & 9.2 & 5.0 & 7.0 & 9.2 & 9.2 & 1.5 & ts, ca \\
\hline VN/H5N1-RG LAIV & 8.7 & 4.2 & 6.2 & 8.7 & 8.7 & 1.5 & ts, ca \\
\hline
\end{tabular}

${ }^{1}$ Reproductive capacity of influenza viruses at different temperatures - (ts and ca phenotype) was assessed by titration in eggs at the permissive $\left(33^{\circ} \mathrm{C}\right)$, elevated $(38,39$, $\left.40^{\circ} \mathrm{C}\right)$ and low $\left(25^{\circ} \mathrm{C}\right)$ temperatures of incubation and expressed as $\mathrm{RCT}_{25,38,39 \text { or } 40}=\log _{10} \mathrm{EID}_{50} / \mathrm{ml}$ at $33^{\circ} \mathrm{C}-\log _{10} \mathrm{EID} \mathrm{D}_{50} / \mathrm{ml}$ at $25,38,39$ or $40^{\circ} \mathrm{C}$. Eggs were incubated for 2 days at $33,38,39$ and $40^{\circ} \mathrm{C}$ and for 6 days at $25^{\circ} \mathrm{C}$.

Table 4: Reproductive capacity of reassortant H5N2 LAIV candidates and parental viruses at different temperatures of incubation in embryonated chicken eggs. 
out a possibility of the Arg-249-Ile mutation to cause the reduced susceptibility, the H5N2 LAIV candidates were tested using the fluorescent NI assay as described in [18]. The results of the NI assay showed the normal inhibition of the NA enzyme activity by the four NAIs tested: zanamivir, oseltamivir, peramivir and laninamivir in accordance with the WHO AVWG criteria (Table 5).

\section{Preclinical evaluation of H5-LAIVs in vivo}

Live monovalent experimental influenza vaccines $\mathrm{A} / 17 /$ turkey/ Turkey/05/133 (H5N2), A/17/Vietnam/04/65107 (H5N2) and A/17/ Vietnam/1203/04-RG (H5N1) were manufactured and released by Pharmaceutical company "Microgen" (Irkutsk, Russia). Preclinical studies of experimental H5-LAIVs (designations for experimental vaccines are the same as for vaccine reassortants: $t / T / H 5 N 2$ LAIV, VN/ H5N2 LAIV and VN/H5N1-RG LAIV respectively) were performed using various animal models.

\section{Toxicology studies of H5-LAIV in rodents}

These tests were performed for one of the experimental vaccines t/T/H5N2 LAIV.

Acute toxicity test in mice and guinea pigs: Single dose administration of $\mathrm{t} / \mathrm{T} / \mathrm{H} 5 \mathrm{~N} 2 \mathrm{LAIV}$ in volume maximal for injection did not cause death, change of behavior, and had no significant effect on the animal's body weight. The kinetics of weight change was similar to one of control non-vaccinated group (Figure 1). The vaccine preparation was found to be well tolerated, and successfully passed limited acute toxicity test in rodents.

Histopathology study in mice: The results of histopathology study reveal that inoculation of H5N2 LAIV in mice, in volume maximal for injection, did not cause any inflammation, destructive or dystrophic changes in systemic organs - liver, kidney, spleen, or heart and no dystrophic changes of neurons were observed in brain. The histopathology picture of samples of organs in vaccine groups was similar to that obtained from control group (data not shown). Administration of H5 LAIV vaccine candidates did not cause gross morphological changes, suggesting positive safety profile of $\mathrm{H} 5 \mathrm{~N} 2$ LAIV.

Sub-acute toxicity study of t/T/H5N2 LAIV in mice and guinea pigs: Two intranasal inoculations of $\mathrm{t} / \mathrm{T} / \mathrm{H} 5 \mathrm{~N} 2 \mathrm{LAIV}$ did not change the external appearance and behavior of mice and guinea pigs and did not affect their consumption of food or water. Dynamics of changes in body weight of animals inoculated with vaccine at doses 200-350 times the human dose did not significantly differ from the control group. We did not find any significant differences in body weight gain in mice and guinea pigs of experimental and placebo treatment groups during the recovery period (Figure 2). These data indicate the absence of the vaccine toxic effects.

\section{Safety and attenuation of H5-LAIV candidates in chickens}

The intravenous pathogenicity index of tested viruses VN/H5N2 LAIV, $\mathrm{t} / \mathrm{T} / \mathrm{H} 5 \mathrm{~N} 2 \mathrm{LAIV}$ and VN/H5N1-RG LAIV in chicken was 0.00 . It means that no birds showed any clinical signs or died during the 10 -day observation period after intravenous vaccine injection. On the third day after intranasal administration at a dose of $6.0 \log _{10} \mathrm{EID}_{50} / 0.1$ $\mathrm{ml}$ cold adapted H5-LAIV reassortants were not isolated from swabs of the upper respiratory tract and of the cloaca, there was no virus isolation from lungs, kidneys, heart and brain tissues. Cold adapted H5-LAIV reassortants were completely attenuated for chickens: they were unable to replicate productively in birds and released to

\begin{tabular}{|c|c|c|c|c|c|c|c|c|}
\hline \multirow{2}{*}{ Virus } & \multicolumn{8}{|c|}{ NA Inhibitor, IC ${ }_{50}(\mathrm{nM})^{1}$} \\
\hline & Zanamivir & Fold $^{2}$ & Oseltamivir & Fold & Peramivir & Fold & Laninamivir & Fold \\
\hline $\mathrm{t} / \mathrm{T} / \mathrm{H} 5 \mathrm{~N} 2$ LAIV & 0.71 & 4 & 0.15 & 1 & 0.18 & 4 & 1.06 & 7 \\
\hline VN/H5N2 LAIV & 0.59 & 3 & 0.15 & 1 & 0.19 & 4 & 1.23 & 8 \\
\hline VN/H5N1-RG LAIV & 0.28 & 1 & 0.07 & 0 & 0.14 & 3 & 0.16 & 1 \\
\hline A/California/07/2009(H1N1)pdm09 3 & 0.19 & 1 & 0.24 & 1 & 0.05 & 1 & 0.16 & 1 \\
\hline A/NorthCarolina/39/2009(H1N1)pdm094 & 0.22 & 1 & 176.73 & 736 & 20.47 & 409 & 0.27 & 1 \\
\hline
\end{tabular}

${ }^{1} \mathrm{IC}_{50}$-drug concentration inhibiting the viral neuraminidase enzyme activity by $50 \%$; values are averages of all test results

${ }^{2}$ Fold-difference compared to the $\mathrm{IC}_{50}$ of the reference sensitive virus;

${ }^{3}$ Reference oseltamivir-sensitive virus; A/California/07/2009 (H1N1) pdm09;

${ }^{4}$ Reference oseltamivir-resistant virus A/North Carolina/39/2009 A (H1N1)pdm09, H275Y.

Table 5: Assessment of influenza virus susceptibility to neuraminidase inhibitors in the fluorescent neuraminidase inhibition assay.

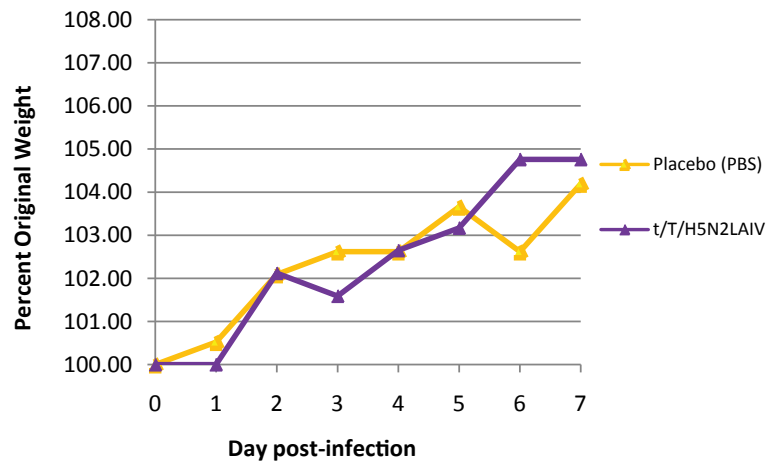

a)

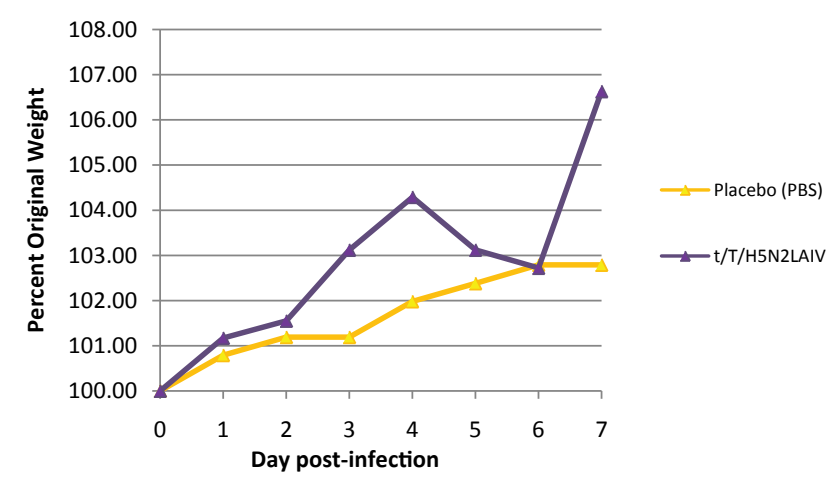

b)

Figure 1: Body weight change of (a) mice after $0.5 \mathrm{ml}$ intraperitoneal injection and (b) guinea pigs after $5 \mathrm{ml}$ intradermal injection of $\mathrm{t} / \mathrm{T} / \mathrm{H} 5 \mathrm{~N} 2 \mathrm{LAIV}$ (9.7 log ${ }_{10}$ $\left.\mathrm{EID}_{50} / \mathrm{ml}\right)$; percentage of day of injection. 
Citation: Larionova N, Kiseleva I, Isakova-Sivak I, Rekstin A, Dubrovina I, et al. (2013) Live Attenuated Influenza Vaccines against Highly Pathogenic H5N1avian Influenza: Development and Preclinical Characterization. J Vaccines Vaccin 4: 208. doi: 10.4172/2157-7560.1000208

Page 7 of 11

the environment. Microscopic examination of tissues collected from intranasally inoculated chickens revealed no lesions in any evaluated birds (two per group of tested virus), and viral antigen staining was not present in any of the tissue examined (Table 6). None of birds presented antibodies detectable by avian influenza specific ELISA on day 14 after intranasal administration.

\section{Safety and attenuation study of H5-LAIV candidates in ferrets}

Groups of ferrets were inoculated with a single dose of each H5-

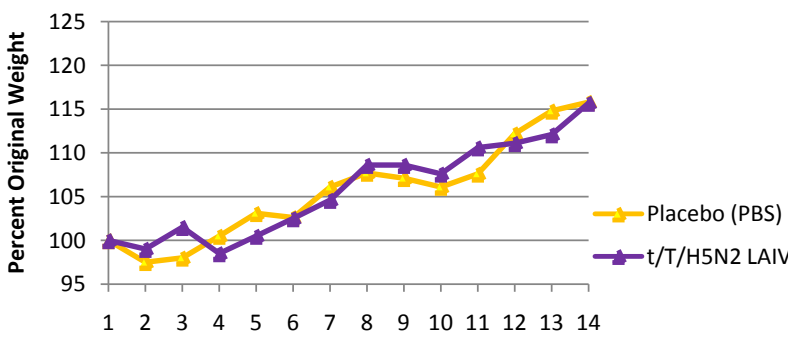

Days post-infection

a)
LAIVs reassortant, with H5N1 HPAIVs and H1N1 LAIV as non-att wild-type and att controls correspondently, or with placebo. No virus was found in the lung and nasal turbinate samples collected from ferrets that received H5-LAIVs reassortants or A/17/California/2009/38 (H1N1) attenuated control virus, while virus production was detected in tested samples obtained from ferrets on day 3 and 5 postinoculation with wild-type non-attenuated control viruses (Table 7). Gross pathology of the lung tissue of LAIVs-inoculated ferrets showed minor cell infiltration and some necrosis, but no clinical signs of illness including weight loss (Figure 3), fever (Figure 4), dehydration, diarrhea,

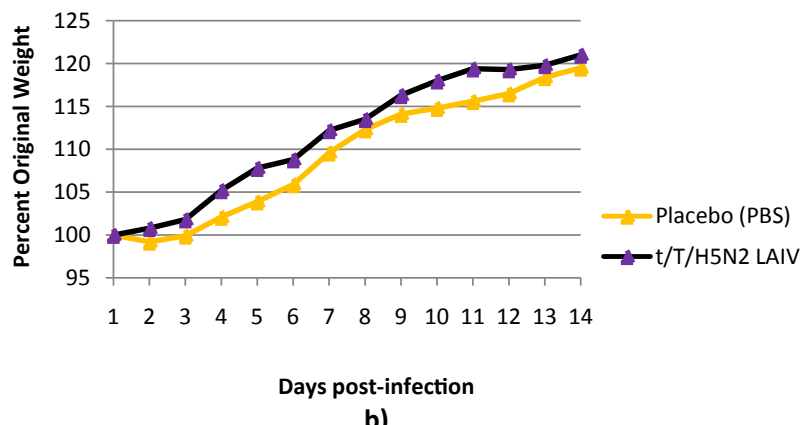

b)

Figure 2: Body weight change of (a) mice and (b) guinea pigs after intranasal inoculation of t/T/H5N2 LAIV $\left(8.7 \log _{10}\right.$ EID $\left._{50}\right)$; percentage of day of administration.

\begin{tabular}{|c|c|c|c|c|c|c|c|c|c|}
\hline \multirow{2}{*}{ Virus } & \multirow{2}{*}{ Morbidity } & \multirow{2}{*}{ Mortality } & \multirow{2}{*}{ ELISA } & \multicolumn{2}{|c|}{$\begin{array}{c}\text { Virus isolation, } I_{50} / \mathrm{ml}^{3} \text { (10 } \\
\text { birds per group) }\end{array}$} & \multicolumn{4}{|c|}{ Virus isolation, $\mathrm{EID}_{50} / \mathrm{gram}^{4}$ ( 2 birds per group) } \\
\hline & & & & Oral & Cloacal & Brain & Heart & Lung & Kidney \\
\hline VN/H5N2 LAIV & $0 / 10^{1}$ & $0 / 10^{1}$ & $0 / 8^{2}$ & $\leq 10^{0.9}$ & $\leq 10^{0.9}$ & $\leq 10^{1.9}$ & $\leq 10^{1.9}$ & $\leq 10^{1.9}$ & $\leq 10^{1.9}$ \\
\hline VN/H5N1-RG LAIV & $0 / 10$ & $0 / 10$ & $0 / 8$ & $\leq 10^{0.9}$ & $\leq 10^{0.9}$ & $\leq 10^{1.9}$ & $\leq 10^{1.9}$ & $\leq 10^{1.9}$ & $\leq 10^{1.9}$ \\
\hline t/T/H5N2 LAIV & $0 / 10$ & $0 / 10$ & $0 / 8$ & $\leq 10^{0.9}$ & $\leq 10^{0.9}$ & $\leq 10^{1.9}$ & $\leq 10^{1.9}$ & $\leq 10^{1.9}$ & $\leq 10^{1.9}$ \\
\hline
\end{tabular}

${ }^{1}$ The number of affected birds/in group of 10 ;

${ }^{2}$ the number of birds with detection of avian influenza virus specific antibodies/in group of 8 ;

${ }^{3}$ the minimum amount detected by the technique is $10^{0.97} \mathrm{EID}_{50} / \mathrm{ml}$; the titer of negative samples is considered to be $\leq 10^{0.9} \mathrm{EID}_{50} / \mathrm{ml}$;

${ }^{4}$ the minimum amount detected by the technique is $10^{1.97} \mathrm{EID}_{50}$ ' $\mathrm{s} / \mathrm{gram}$ of tissue; the titer of negative samples is considered to be $\leq 10^{1.9} \mathrm{EID}_{50}$ 's/gram of tissue. All the tissues were prepared as a $10 \%$ weight/volume suspension.

Table 6: Attenuated phenotype of H5-LAIV candidates in experiments on chickens, the third day after intranasal administration.

\begin{tabular}{|c|c|c|c|c|c|}
\hline \multirow{2}{*}{ Virus } & \multirow{2}{*}{$\begin{array}{l}\text { Virus dose, } \log _{10} \\
\text { EID }_{50} / \text { ferret }\end{array}$} & \multirow{2}{*}{ Day p.i. } & \multicolumn{2}{|c|}{ Virus load $\left(\log _{10}\right.$ PFU/g) } & \multirow{2}{*}{ Lung lesions score: individual (average) } \\
\hline & & & Lung & Nose & \\
\hline \multirow{4}{*}{ VN/H5N2 LAIV } & \multirow{2}{*}{6.0} & 3 & 0 & 0 & $0 ; 1 ; 0$ \\
\hline & & 5 & 0 & 0 & $2 ; 2 ; 2$ \\
\hline & \multirow{2}{*}{7.0} & 3 & 0 & 0 & $0 ; 0 ; 0$ \\
\hline & & 5 & 0 & 0 & $3 ; 2 ; 3$ \\
\hline \multirow{4}{*}{ VN/H5N1-RG LAIV } & \multirow{2}{*}{6.0} & 3 & 0 & 0 & $0 ; 0 ; 0$ \\
\hline & & 5 & 0 & 0 & $0 ; 0 ; 2$ \\
\hline & \multirow{2}{*}{7.0} & 3 & 0 & 0 & $0 ; 0 ; 2$ \\
\hline & & 5 & 0 & 0 & $0 ; 0 ; 2$ \\
\hline \multirow{4}{*}{$\mathrm{t} / \mathrm{T} / \mathrm{H} 5 \mathrm{~N} 2 \mathrm{LAIV}$} & \multirow{2}{*}{6.0} & 3 & 0 & 0 & $2 ; 0 ; 0$ \\
\hline & & 5 & 0 & 0 & $0 ; 0 ; 0$ \\
\hline & \multirow{2}{*}{7.0} & 3 & 0 & 0 & $0 ; 2 ; 2$ \\
\hline & & 5 & 0 & 0 & $0 ; 0 ; 2$ \\
\hline \multirow{2}{*}{ A/turkey/Turkey/1/2005 (H5N1) HPAIV } & \multirow{2}{*}{7.0} & 3 & 4.15 & 4.24 & $5 ; 5 ; 5$ \\
\hline & & 5 & 3.89 & 4.17 & $5 ; 5 ; 5$ \\
\hline \multirow{2}{*}{ A/Vietnam/1194/2004 (H5N1) HPAIV } & \multirow{2}{*}{7.0} & 3 & 4.36 & 4.20 & $5 ; 5 ; 5$ \\
\hline & & 5 & 4.25 & 3.89 & $5 ; 5 ; 5$ \\
\hline \multirow{2}{*}{ A/17/California/2009/38 (H1N1) LAIV } & \multirow{2}{*}{7.0} & 3 & 0 & 0 & $0 ; 0 ; 0$ \\
\hline & & 5 & 0 & 0 & $0 ; 0 ; 0$ \\
\hline \multirow{2}{*}{ Placebo (PBS) } & \multirow{2}{*}{ NO } & 3 & 0 & 0 & $0 ; 0 ; 0$ \\
\hline & & 5 & 0 & 0 & $0 ; 0 ; 0$ \\
\hline
\end{tabular}

Virus load was determined in tested samples by plaque titration in MDCK cells. Three animals in each group were tested. Histopathological parameters were scored as: 0 - absent (no visible changes), 1 - minimal, 2 - slight, 3 - moderate, 4 - strong, 5 - severe.

Table 7: Attenuated phenotype of H5-LAIV candidates in experiments on ferrets after intranasal administration. 
or dyspnea, whereas HPAIVs infected ferrets displayed complete lungs infiltration and necrosis of all lobes, fever and significant weight loss.

\section{Immunogenicity and protection study of H5-LAIV candidates in ferrets}

Groups of animals were immunized with two doses of $7.0 \log _{10}$ EID $_{50}$ H5 LAIV candidates 28 days apart, challenged with a lethal dose of H5N1 HPAIV two weeks later, and sacrificed on day 3 or 14 postchallenge. Control immunized or non immunized animals received placebo.

In all cases H5 LAIVs elicited homologous HAI titers in vaccinated ferrets, which level significantly increased by following

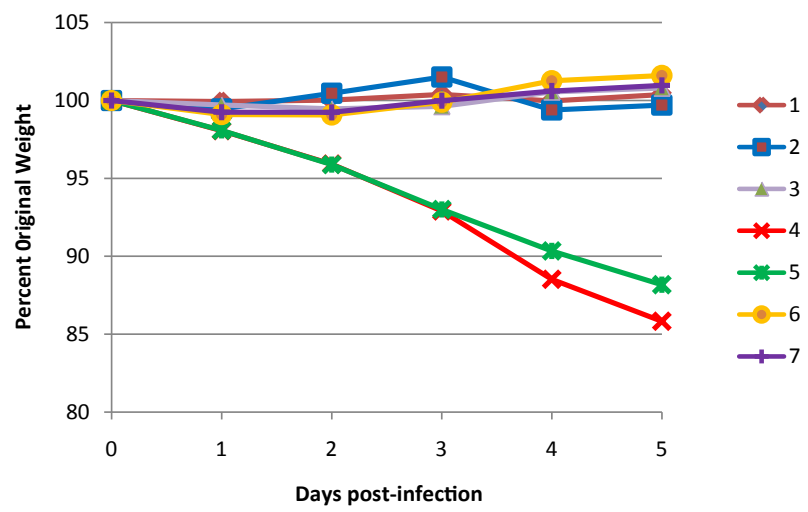

Figure 3: Body weight change among studied groups* of vaccinated ferrets; percentage of day of administration.

${ }^{*} 6$ animals in group were intranasally inoculated with7.0 $\log _{10} E D_{50}$ of:

1 - VN/H5N1-RG LAIV;

2 - VN/H5N2 LAIV;

3 - t/T/ H5N2 LAIV;

4 - H5N1 A/Vietnam/1194/2004;

5 - H5N1 A/turkey/Turkey/1/2005

6 - H1N1 A/California/2009/38 LAIV;

7 - Placebo (PBS)

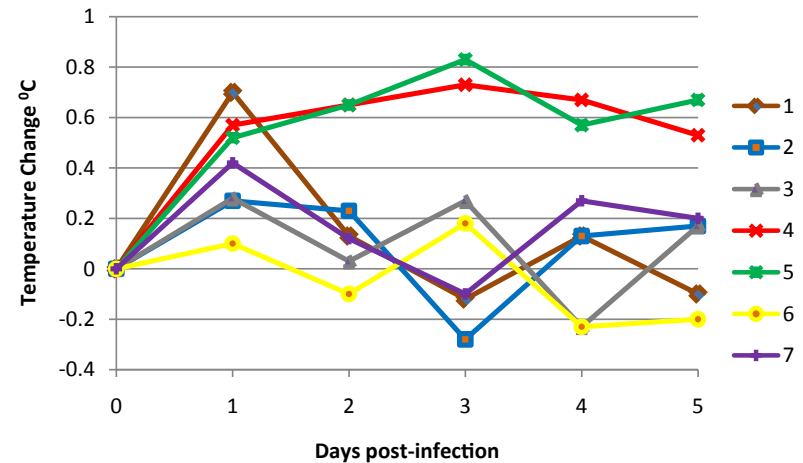

Figure 4: Body temperature change among studied groups of vaccinated ferrets; difference from baseline.

*6 animals in group were intranasally inoculated with7.0 $\log _{10} E \mathrm{EI}_{50}$ of:

1 - VN/H5N1-RG LAIV;

2 - VN/H5N2 LAIV;

3 - $t / T /$ H5N2 LAIV;

4 - H5N1 A/Vietnam/1194/2004;

5 - H5N1 A/turkey/Turkey/1/2005;

6 - H1N1 A/California/2009/38 LAIV;

7 - Placebo (PBS) booster immunization (Table 8). Although the absolute rise of the homologous antibody titers in ferrets immunized with $\mathrm{t} / \mathrm{T} / \mathrm{H} 5 \mathrm{~N} 2 \mathrm{LAIV}$ was lower (antibodies GMT between week 4/week 6 was 12.6/127.0 respectively) than an immune response to the heterologous antigen A/Vietnam/1203/04 (clade 1) (antibodies GMT between week 4/ week 6 was 127.0/508.0 respectively), the degree of growth in serum antibody titer to the homologous virus $\mathrm{A} /$ turkey/Turkey/01/2005 was significantly higher after revaccination (10.1 versus 4.0$)$. It is notable that 7:1 VN/H5N2 LAIV and 6:2 VN/H5N1-RG LAIV showed virtually identical immunogenicity. H5N2 LAIV vaccine candidate based on A/ turkey/Turkey/01/2005 (H5N1) (clade 2.2) strain induced broader immunity based on cross-reactive HAI titers against earlier varieties of $\mathrm{H} 5 \mathrm{~N} 1$ virus such as viruses of clades 1, 2.1 and other representatives of clade 2.2 virus.

All tested H5 LAIV candidates protected ferrets from challenge with H5N1 HPAI viruses, in contrast with placebo-vaccinated animals. After challenge with lethal viruses, placebo-vaccinated controls displayed signs of neurological dysfunction, showed severe symptoms of infection including virus shedding, significant weight loss (approximately $\geq 20 \%$ of their original body weight) (Figure 5), temperature elevation - maximum temperature increase compared to average baseline temperature was $1.5^{\circ} \mathrm{C}$ to $2^{\circ} \mathrm{C}$ (Figure 6), caused severe macroscopy lung lesions etc. No virus was detected in the lungs of vaccinated ferrets on day 3 post-challenge, while wild-type $\mathrm{H} 5 \mathrm{~N} 1$ viruses were detectable in the lungs after challenge of placebo treated group (Table 9). No lung pathogenesis was detectable in the tested tissues on day 14 post-challenge in vaccinated groups. Challenge viruses were fatal for placebo-vaccinated ferrets on day 6 or 7 . In contrast, ferrets vaccinated with LAIVs did not exhibit overt clinical signs of infection and survived the full experimental period. Vaccinated groups didn't show any significant loss of weight after the challenge (Figure 5). All vaccinated animals didn't shed challenge virus or shed it in low titers.

\section{Discussion}

Classical reassortment of the MDV-Len17 with NIBRG-23 and VN-PR/CDC-RG (H5N1) resulted in the $\mathrm{H} 5 \mathrm{~N} 2$ viruses that contained six internal genes of MDV. However, the generated reassortants also inherited the NA gene segment from the MDV (reassortant genotype 7:1).

The problem in obtaining the desired 6:2 genomic composition may be a result of co-infection of avian and human viruses. In some cases avian-human 6:2 reassortants were difficult to generate despite repeated attempts [28]. The functional incompatibilities between the viral proteins or RNA segments of two differing strains may lead to the segments mismatch that limits the reassortment efficiency [29-31]. Another group of authors [32] faced a similar problem when trying to create $6: 2$ reassortants based on the same parental viruses - VN/ PR/CDC-RG (H5N1) and MDV-Len17 (H2N2). The result of their attempts also was the reassortant with genome formula 7:1. One of the possible reasons for the complexity of inheritance of avian virus origin NA in avian (avian/PR reassortants in our study) and attenuated human viruses reassortment may be associated with higher temperature optimum of avian influenza virus polymerases. At the same time no difficulties arisen in the generation of 6:2 VN-PR/CDC-RG (H5N1) reassortant by reverse genetic.

However, in the case of generating a LAIV vaccine candidate for protecting humans against HPAIV, reassortants carrying the HA gene of pathogenic H5-virus and other genes from an attenuated MDV can be the better choice as they could provide extra level of safety for the LAIV candidate. The HA of H5N2 LAIV reassortants is modified for 
Page 9 of 11

\begin{tabular}{|c|c|c|c|c|c|c|c|}
\hline \multirow[b]{2}{*}{ Test article } & \multirow[b]{2}{*}{$\begin{array}{l}\text { Week post } \\
\text { vaccination }\end{array}$} & \multicolumn{6}{|c|}{ H5N1 antigen for HAl test (GMT'1) } \\
\hline & & Vietnam $^{2}$ (clade 1) & $\begin{array}{l}\text { Indonesia3 } \\
\text { (clade 2.1) }\end{array}$ & Turkey $^{4}$ (clade 2.2) & $\begin{array}{l}\text { Bar-h goose }^{5} \\
\text { (clade 2.2) }\end{array}$ & $\begin{array}{l}\text { W.swan } \\
\text { (clade 2.2) }\end{array}$ & Anhui ${ }^{7}$ (clade 2.3) \\
\hline \multirow{4}{*}{$\begin{array}{l}\text { VN/H5N2 LAIV } \\
\text { (clade 1) }\end{array}$} & 0 & 10.0 & 10.0 & 10.0 & 10.0 & 10.0 & 10.0 \\
\hline & 4 & 40.0 & 11.2 & 10.0 & 10.0 & 14.1 & 10.0 \\
\hline & 6 & 403.1 & 10.0 & 20.0 & 20.0 & 31.8 & 17.8 \\
\hline & $6 / 4$ & $10.1^{8}$ & 1.2 & 2.0 & 2.0 & 2.3 & 1.8 \\
\hline \multirow{4}{*}{$\begin{array}{l}\text { VN/H5N1-RG LAIV } \\
\quad \text { (clade 1) }\end{array}$} & 0 & 10.0 & 10.0 & 10.0 & 10.0 & 10.0 & 10.0 \\
\hline & 4 & 50.4 & 11.2 & 10.0 & 10.0 & 22.5 & 10.0 \\
\hline & 6 & 285.1 & 35.6 & 14.1 & 14.1 & 127.0 & 17.8 \\
\hline & $6 / 4$ & 5.7 & 3.2 & 1.4 & 1.4 & 5.6 & 1.8 \\
\hline \multirow{4}{*}{$\begin{array}{l}\text { t/T/H5N2 LAIV } \\
\text { (clade } 2.2 \text { ) }\end{array}$} & 0 & 10.0 & 10.0 & 10.0 & 10.0 & 10.0 & 10.0 \\
\hline & 4 & 127.0 & 10.0 & 12.6 & 14.1 & 10.0 & 10.0 \\
\hline & 6 & 508.0 & 44.9 & 127.0 & 113.1 & 40.0 & 22.5 \\
\hline & $6 / 4$ & $4.0^{1}$ & 4.5 & 10.1 & 8.0 & 4.0 & 2.3 \\
\hline \multirow{4}{*}{ PBS } & 0 & 10.0 & 10.0 & 10.0 & 10.0 & 10.0 & 10.0 \\
\hline & 4 & 10.0 & 10.0 & 10.0 & 10.0 & 10.0 & 10.0 \\
\hline & 6 & 10.0 & 10.0 & 10.0 & 10.0 & 10.0 & 10.0 \\
\hline & $6 / 4$ & 1.0 & 1.0 & 1.0 & 1.0 & 1.0 & 1.0 \\
\hline
\end{tabular}

Vaccination dose: $7.0 \log _{10} I D_{50} /$ ferret. Blood samples were collected at day 28 (week 4) and at day 42 (week 6) post immunization.

${ }^{1}$ Geometric mean titer; each group contained six animals; ${ }^{2} \mathrm{~A} /$ Vietnam/1203/04 (H5N1); ${ }^{3} \mathrm{~A} /$ Indonesia/5/05 (H5N1); ${ }^{4} \mathrm{~A} /$ turkey/Turkey/1/05 (H5N1); ${ }^{5} \mathrm{~A} / \mathrm{bar}-\mathrm{headed}$ goose/ Mongolia/1/2005 (H5N1); ${ }^{6} \mathrm{~A} /$ whooper swan/Mongolia/244/05 (H5N1); ${ }^{7} \mathrm{~A} /$ Anhui/1/05 (H5N1). ${ }^{8} \mathrm{~A}$ fourfold or greater rise in titer of antibodies against virus hemagglutinin in sera of ferrets between the first (week 4) and second sample (week 6) was considered as seroconversion.

Table 8: Immunogenicity of H5N2 LAIV candidates in experiments on ferrets.

\begin{tabular}{|c|c|c|c|c|c|c|c|c|c|}
\hline \multirow{3}{*}{$\begin{array}{l}\text { LAIV immunization, } \\
\left.\text { (7 } \log _{10} \text { EID }_{50} / \text { ferret }\right) / \\
\text { Placebo control }\end{array}$} & \multicolumn{9}{|c|}{ H5N1 HPAIV challenge virus/PBS load ${ }^{1}$} \\
\hline & \multicolumn{3}{|c|}{ A/Vietnam/1194/2004 } & \multicolumn{3}{|c|}{ A/turkey/Turkey/1/2005 } & \multicolumn{3}{|c|}{ PBS } \\
\hline & $\begin{array}{l}\text { Placebo } \\
\text { control }\end{array}$ & Nose (D3) & $\begin{array}{l}\text { Nasal wash } \\
\text { (D3/D5) }\end{array}$ & Lungs (D3) & Nose (D3) & $\begin{array}{l}\text { Nasal wash } \\
\text { (D3/D5) }\end{array}$ & Lungs (D3) & Nose (D3) & $\begin{array}{c}\text { Nasal wash } \\
\text { (D3/D5) }\end{array}$ \\
\hline VN/H5N2 LAIV & 0 & 1.40 & $2.80 / 0$ & nd & nd & nd & 0 & 0 & 0 \\
\hline VN/H5N1-RG LAIV & 0 & 1.52 & $2.88 / 0$ & nd & nd & nd & 0 & 0 & 0 \\
\hline t/T/H5N2 LAIV & $n d^{2}$ & nd & nd & 0 & 1.45 & $2.23 / 0$ & 0 & 0 & 0 \\
\hline Placebo (PBS) & 4.86 & 5.10 & $5.96 / 4.84$ & 4.82 & 4.96 & $5.80 / 4.53$ & 0 & 0 & 0 \\
\hline
\end{tabular}

${ }^{1}$ Virus load expressed in $\log _{10}$ PFU/g for lung and nasal turbinates supernatants or log10 PFU/ml for nasal washes;

${ }^{2}$ nd - not done, challenge with heterogeneous H5N1-HPAIV was not performed;

${ }^{3}$ D3, D5 - day post-infection with challenged H5N1-HPAIV or placebo inoculation.

Table 9: Virus isolation from respiratory tract of ferrets immunized with H5-LAIV candidates after challenge with H5N1 HPAIV.

reduced virulence, but it has been observed that avian influenza NA may also be involved in the manifestation of the pathogenic properties of the virus in human cells [33]. The presence of NA of cold-adapted $\mathrm{MDV}$, together with genetically modified H5-HA may provide an extra layer of safety for attenuation of H5N2 LAIV candidate against highly pathogenic avian influenza virus of H5N1subtype. As for the immune response, antibodies to the influenza virus HA are known to be the main component of the protection against human [34] and avian influenza viruses [35]. Thus the evaluation of the individual contributions of each of the surface proteins to the induction of HPAIVneutralizing serum antibodies and protective immunity showed that immunization of chickens with Newcastle disease virus expressing $\mathrm{H} 5$ hemagglutinin of avian influenza virus single or in combination with avian N1 neuraminidase caused in both cases $100 \%$ protection from challenge infection with H5N1 HPAIVs. The avian NA in the vaccine preparation did not improve protection generated by antibodies to $\mathrm{H} 5$ HA. Immunity to NA extended survival but did not prevent death from HPAIV challenge [36].

Attenuated phenotype of H5N2 LAIV candidates is critically important for eventual testing them in human trials and our study confirmed it by virological, molecular genetics methods and in the experiments on the laboratory animals. Virological analysis of the properties of the vaccine candidates confirmed their $t s$ and $c a$ phenotype. Nucleotide composition analysis of the reassortants genome confirmed the stability of all attenuating mutations typical for MDV-Len17. Two additional mutations that appeared in the HA gene of VN/H5N2 LAIV are located in areas that should not affect the antigenic sites, and do not change the antigenic properties of the virus. The same amino acid change in NA of both H5N2 LAIV reassortants might be explained by the possible presence of a minor population with this mutation in original MDV-L17 stock, or this mutation may be required for compatibility of NA with the heterologous HA protein. Despite the fact that the amino acid change in NA common for both H5N2 LAIV reassortants does not affect any significant structural and enzymatic domains of the neuraminidase molecule, does not influence on specific to MDV-L17 high growth rate of 7:1 reassortants at optimal temperature, we found it desirable to check reassortants with mutant NA for their sensitivity to neuraminidase inhibitors. The results of the NI assay showed unchanged inhibition of the NA enzyme activity by the four NAIs tested. Therefore, the genotypic and phenotypic data were consistent with the drug sensitive phenotype of the reassortants made on the backbone of MDV-L17: 6:2 with NA of HPAIV or 7:1 with mutant NA of MDV-L17.

The results of experiments in mice, guinea pigs, chickens and 


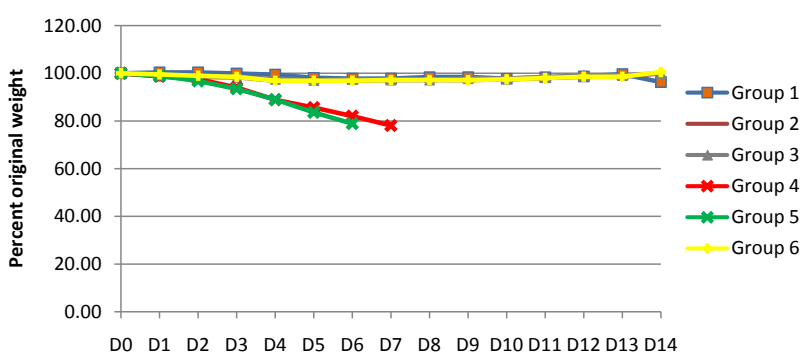

Figure 5: Body weight change among studied groups of vaccinated ferrets post-challenged with a lethal dose of H5N1 HPAIV; percentage of day of administration.

${ }^{*} 6$ animals in group were intranasally immunized with two doses of $7.0 \log _{10}$ EID $_{50}$ H5 LAIV candidates 28 days apart, on day 42 challenged with $6.0 \log _{10}$ EID $_{50}$ of H5N1 HPAIV. Control non immunized animals received placebo. Observation period-14 days post-challenge.

Groups of ferrets:

1 - immunized with VN/H5N2 LAIV, challenged with A/Vietnam/1194/2004 (H5N1);

2 - immunized with VN/H5N1-RG LAIV, challenged with A/Vietnam/1194/2004 (H5N1);

3 - immunized with $\mathrm{t} / \mathrm{T} / \mathrm{H} 5 \mathrm{~N} 2$, challenged with A/turkey/Turkey/1/2005 (H5N1); 4 - immunized with Placebo (PBS), challenged with H5N1 A/Vietnam/1194/2004 5 - immunized with Placebo (PBS), challenged with H5N1 A/turkey/ Turkey/1/2005;

6 - immunized with Placebo (PBS), challenged with Placebo (PBS)

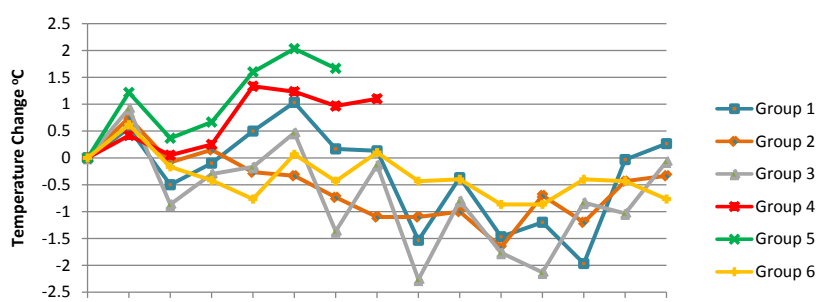

$\begin{array}{lllllllllllllll}\text { D0 } & \text { D1 } & \text { D2 } & \text { D3 } & \text { D4 } & \text { D5 } & \text { D6 } & \text { D7 } & \text { D8 } & \text { D9 } & \text { D10 } & \text { D11 } & \text { D12 } & \text { D13 } & \text { D14 }\end{array}$

Figure 6: Body temperature change among studied groups* of vaccinated ferrets post-challenged with a lethal dose of H5N1 HPAIV; difference from baseline.

*6 animals in group were intranasally immunized with two doses of $7.0 \log _{10}$ EID $_{50}$ H5 LAIV candidates 28 days apart, on day 42 challenged with $6.0 \log _{10}$ EID $_{50}$ of H5N1 HPAIV. Control non immunized animals received placebo. Observation period - 14 days post-challenge.

Groups of ferrets:

1 - immunized with VN/H5N2 LAIV, challenged with A/Vietnam/1194/2004 (H5N1);

2 - immunized with VN/H5N1-RG LAIV, challenged with A/Vietnam/1194/2004 (H5N1);

3 - immunized with $\mathrm{t} / \mathrm{T} / \mathrm{H} 5 \mathrm{~N} 2$, challenged with A/turkey/Turkey/1/2005 (H5N1) 4 -immunized with Placebo (PBS), challenged with H5N1 A/Vietnam/1194/2004; 5 - immunized with Placebo (PBS), challenged with H5N1 A/turkey/ Turkey/1/2005;

6 - immunized with Placebo (PBS), challenged with Placebo (PBS).

ferrets confirmed safety and attenuation phenotype of tested H5 LAIV reassortants.

Because of the high body temperature of chickens the $t s$, $c a$ vaccine strains were unable to replicate productively in birds, generate progeny that might be detected by the methods used and cause immune response in birds.

Immunogenicity and protective efficacy of LAIV reassortants were demonstrated in ferret model. A/17/turkey/Turkey/05/133 (H5N2), A/17/Vietnam/04/65107 (H5N2) (both with genomic composition
7:1) and A/17/Vietnam/1203/04-RG (H5N1) (genomic composition 6:2) LAIV candidates were equally safe, immunogenic and effective in protecting ferrets from severe disease, mortality and pathology and significantly reduced challenge virus replication. The complete protection against lethal challenge in ferrets was achieved by means of two vaccinations with LAIVs. Interestingly, ferrets immunized with $\mathrm{t} / \mathrm{T} / \mathrm{H} 5 \mathrm{~N} 2$ LAIV demonstrated cross-immune response to the virus A/Vietnam/1203/04 (clade 1) higher than to the homologous wild virus $\mathrm{A} /$ turkey/Turkey/01/2005. Such situations are described in the literature and explained by the appearance of "escape" mutations in evolving viruses [37].

These studies demonstrated that LAIV vaccine candidates based on MDV-L17 backbone and carrying hemagglutinin of HPAI viruses are efficacious in inducing protective immunity against the lethal challenge with a homologous wild-type virus. It is demonstrated that H5 live attenuated influenza vaccines induced comprehensive cross-protection against disease outcomes and upper respiratory tract replication of H5N1 highly pathogenic avian influenza viruses.

Thus, H5N2 reassortants, obtained by methods of classical reassortment in eggs are promising vaccines for further evaluation in humans as potential pandemic LAIV candidates against H5N1 HPAI viruses. The widest range of cross-protection demonstrated LAIV against virus $\mathrm{A} /$ turkey/Turkey/1/05 (H5N1).

\section{Acknowledgement}

Authors are thankful to Program for Appropriate Technologies in Health (PATH) for the financial support of this study. We thank the $\mathrm{CDC}$ and $\mathrm{WHO}$ for the transfer to us of RG-generated H5N1 reassortant influenza viruses for inactivated vaccines. We wish to thank MA Zaitseva, MV Melikhova and KL Avakian for histological studies of H5-LAIVs toxicity in mice.

\section{References}

1. Capua I, Alexander DJ (2007) Avian influenza infections in birds--a moving target. Influenza Other Respi Viruses 1: 11-18.

2. Key Facts About Avian Influenza (Bird Flu) and Highly Pathogenic Avian Influenza A (H5N1) Virus.

3. Options for Live Attenuated Influenza Vaccines (LAIV).

4. http://who.int/immunization/sage/SAGE_H5N1_26Mayb.pdf

5. http://www.who.int/wer/2005/wer8033.pdf

6. Rudenko LG, Slepushkin AN, Monto AS, Kendal AP, Grigorieva EP, et al. (1993) Efficacy of live attenuated and inactivated influenza vaccines in schoolchildren and their unvaccinated contacts in Novgorod, Russia. J Infect Dis 168: 881-887.

7. Rudenko LG, Alexandrova GI (2001) Current strategies for the prevention of influenza by the Russian cold-adapted live influenza vaccine among different populations. International Congress Series 1219: 945-950.

8. Wareing MD, Marsh GA, Tannock GA (2002) Preparation and characterisation of attenuated cold-adapted influenza A reassortants derived from the A Leningrad/134/17/57 donor strain. Vaccine 20: 2082-2090.

9. Kiseleva I, Klimov A, Su Q, Szymkowiak C, Toner TG, et al. (2004) Role of individual genes of the A/Leningrad/134/17/57 (H2N2) cold-adapted donor strain in manifestation of the temperature-sensitive phenotype of reassortant influenza A viruses. International Congress Series 1263: 547-550.

10. Webby RJ, Perez DR, Coleman JS, Guan Y, Knight JH, et al. (2004) Responsiveness to a pandemic alert: use of reverse genetics for rapid development of influenza vaccines. Lancet 363: 1099-1103.

11. Gustin KM, Maines TR, Belser JA, van Hoeven N, Lu X, et al. (2011) Comparative immunogenicity and cross-clade protective efficacy of mammalian cell-grown inactivated and live attenuated $\mathrm{H} 5 \mathrm{~N} 1$ reassortant vaccines in ferrets. J Infect Dis 204: 1491-1499.

12. Larionova N, Kiseleva I, Dubrovina I, Bazhenova E, Rudenko L (2011) 
Citation: Larionova N, Kiseleva I, Isakova-Sivak I, Rekstin A, Dubrovina I, et al. (2013) Live Attenuated Influenza Vaccines against Highly Pathogenic H5N1avian Influenza: Development and Preclinical Characterization. J Vaccines Vaccin 4: 208. doi: 10.4172/2157-7560.1000208

Page 11 of 11

Peculiarities of reassortment of cold-adapted influenza A master donor virus with viruses possessed avian origin HA and NA H5N1. Influ Respi Viruses 5: 347-349.

13. Rudneva IA, Timofeeva TA, Shilov AA, Kochergin-Nikitsky KS, Varich NL, et al. (2007) Effect of gene constellation and postreassortment amino acid change on the phenotypic features of H5 influenza virus reassortants. Arch Virol 152: 1139-1145.

14. Biacchesi S, Skiadopoulos MH, Yang L, Murphy BR, Collins PL, et al. (2005) Rapid human metapneumovirus microneutralization assay based on green fluorescent protein expression. J Virol Methods 128: 192-197.

15. Anderson T, Capua I, Dauphin G, Donis R, Fouchier R, et al. (2010) FAO-OIEWHO Joint Technical Consultation on Avian Influenza at the Human-Animal Interface. Influenza Other Respi Viruses 4 Suppl 1: 1-29.

16. Klimov Al, Cox NJ (1995) PCR restriction analysis of genome composition and stability of cold-adapted reassortant live influenza vaccines. J Virol Methods 52: $41-49$

17. Kiseleva IV, Voeten JT, Teley LC, Larionova NV, Dubrovina IA, et al. (2011) [Genome composition analysis of the reassortant influenza viruses used in seasonal and pandemic live attenuated influenza vaccine]. Mol Gen Mikrobiol Virusol: 29-36.

18. Hurt AC, Okomo-Adhimabo M, Gubareva LV (2012) The fluorescence neuraminidase inhibition assay: a functional method for detection of influenza virus resistance to the neuraminidase inhibitors. Methods Mol Biol 865: 115-125.

19. [No authors listed] (2012) Meetings of the WHO working group on surveillance of influenza antiviral susceptibility â€“ Geneva, November 2011 and June 2012. Wkly Epidemiol Rec 87: 369-374.

20. http://www.oie.int/fileadmin/Home/eng/Health_standards/tahm/2.03.04_Al.pdf

21. Giles BM, Ross TM (2011) A computationally optimized broadly reactive antigen (COBRA) based H5N1 VLP vaccine elicits broadly reactive antibodies in mice and ferrets. Vaccine 29: 3043-3054

22. Tobita K (1975) Permanent canine kidney (MDCK) cells for isolation and plaque assay of influenza B viruses. Med Microbiol Immunol 162: 23-27.

23. Tobita K, Sugiura A, Enomote C, Furuyama M (1975) Plaque assay and primary isolation of influenza A viruses in an established line of canine kidney cells (MDCK) in the presence of trypsin. Med Microbiol Immunol 162: 9-14.

24. Nguyen HT, Fry AM, Gubareva LV (2012) Neuraminidase inhibitor resistance in influenza viruses and laboratory testing methods. Antivir Ther 17: 159-173.

25. Stevens J, Blixt O, Tumpey TM, Taubenberger JK, Paulson JC, et al. (2006) Structure and receptor specificity of the hemagglutinin from an $\mathrm{H} 5 \mathrm{~N} 1$ influenza virus. Science 312: 404-410.
26. Stevens J, Blixt O, Glaser L, Taubenberger JK, Palese P, et al. (2006) Glycan microarray analysis of the hemagglutinins from modern and pandemic influenza viruses reveals different receptor specificities. J Mol Biol 355: 1143-1155.

27. Klimov AI, Kiseleva IV, Alexandrova GI, Cox NJ (2001) Genes coding for polymerase proteins are essential for attenuation of the cold-adapted $A$ Leningrad/134/17/57 (H2N2) influenza virus. International Congress Series 1219: 955-959.

28. Subbarao K, Webster RG, Kawaoka Y, Murphy BR (1995) Are there alternative avian influenza viruses for generation of stable attenuated avian-human influenza A reassortant viruses? Virus Res 39: 105-118.

29. Greenbaum BD, Li OT, Poon LL, Levine AJ, Rabadan R (2012) Vira reassortment as an information exchange between viral segments. Proc Natl Acad Sci U S A 109: 3341-3346.

30. Gao Q, Palese P (2009) Rewiring the RNAs of influenza virus to prevent reassortment. Proc Natl Acad Sci U S A 106: 15891-15896.

31. Li C, Hatta M, Watanabe S, Neumann G, Kawaoka Y (2008) Compatibility among polymerase subunit proteins is a restricting factor in reassortment between equine H7N7 and human H3N2 influenza viruses. J Virol 82: 1188011888.

32. Gambaryan AS, Lomakina NF, Boravleva EY, Kropotkina EA, Mashin VV, et al. (2012) Comparative safety, immunogenicity, and efficacy of several anti-H5N1 influenza experimental vaccines in a mouse and chicken models (Testing of killed and live H5 vaccine). Influenza Other Respi Viruses 6: 188-195.

33. de Wit E, Munster VJ, van Riel D, Beyer WE, Rimmelzwaan GF, et al. (2010) Molecular determinants of adaptation of highly pathogenic avian influenza H7N7 viruses to efficient replication in the human host. J Virol 84: 1597-1606.

34. Wilschut JC, McElhaney LE, Palache AM (2006) Rapid Reference Influenza. (2nd edn) Mosby/Elsevier Science, London.

35. Gillim-Ross L, Subbarao K (2007) Can immunity induced by the human influenza virus $\mathrm{N} 1$ neuraminidase provide some protection from avian influenza H5N1 viruses? PLoS Med 4: e91.

36. Nayak B, Kumar S, DiNapoli JM, Paldurai A, Perez DR, et al. (2010) Contributions of the avian influenza virus HA, NA, and M2 surface proteins to the induction of neutralizing antibodies and protective immunity. J Virol 84 2408-2420.

37. Timofeeva TA, Rudneva IA, Mochalova LV, Bovin NV, Kaverin NV (2013) [Effect of mutations changing the antigenic specificity on the receptor-binding activity of the influenza virus hemagglutinin of $\mathrm{H} 1$ and $\mathrm{H} 5$ subtypes]. Vop Virusol 58: 24-27. 